\title{
Air accident investigation among regulatory agencies
}

\author{
Marcia Fajer ${ }^{\mathrm{a}}$ and Frida Marina Fischer ${ }^{\mathrm{b}}$ \\ ${ }^{a}$ Defense State Ministry, Aeronautics Air Command, São Paulo, Brazil \\ ${ }^{b}$ Department of Environmental Health, University of São Paulo, Brazil
}

\begin{abstract}
The aim of this manuscript is to describe and compare regulatory aviation agencies according to their subordination and attributions to investigate air accidents. Possible consequences in identifying the contributory factors are also presented. Distinct procedures investigating air accidents among agencies lead to a lack of standardization of the statistics, making it difficult to analyze the data globally. Separately the information does not configure the entire scenario of what occurred, affecting the analysis and subsequent interventions. We recommend a joint and collaborative work between the different committees that operate in the investigation of air accidents.
\end{abstract}

Keywords: air accidents, regulatory agencies, accidents investigation, organizational factors, standardization

\section{Introduction}

Data from the website of the Brazilian Accident Prevention and Investigation Center (Centro de Investigação e Prevenção de Acidentes AeronáuticosCENIPA [1]) show an increase of the number of air accidents that occurred in Brazil since 2006. Several factors can be considered to explain such increase. Among them, air operation safety indicators such as: hours flown, fleet size, number of takeoffs, air accident classification (severity, fatal injuries, number of deceased, frequency, etc.).

Nowadays there is no standardization of the procedures to investigate the factors that might be directly or indirectly associated to air accidents. The National Transportation Safety Board (NTSB) uses as criterion to classify its statistics the number of accidents per type of aviation and per million of hours flown, analyzing separately the types of lesion and the contributory factors. [5].
The European Aviation Safety Agency (EASA) presented the statistics per 10 million hours flown, per type of equipment, separating airplanes from helicopters, per type of aviation and per number of fatalities [3].

The aim of this manuscript is to compare regulating agencies according to their subordination and attributions to investigate air accidents, evaluating possible consequences in identifying the contributory factors.

\section{Method}

The International Civil Aviation Organization (ICAO) regulations suggest that all countries must have their own investigation agency [4].

In this study the agencies that investigate air accidents were analyzed per organization structure, operation and investigation system, and for government ties. For such analysis were chosen agencies from Brazil, United States and European Union, for being major global aviation centers, considering the

\footnotetext{
*Corresponding author. E-mail: marcia.fajer@gmail.com

This manuscript is part of the Master Dissertation presented at the Graduate Program in Public Health, School of Public Health, University of São Paulo, Brazil, 2009.
} 
fleets' size and the manufacturing of airships and equipment.

Data on the American (NSTB), European (EASA) and Brazilian (CENIPA) investigation agencies were obtained via bibliography and documents. It was also compared the procedures of the "go team" at the time of the air accident.

\section{Results and discussion}

It was observed that only NTSB and CENIPA work directly with the investigation, being the former one completely independent and the latter subordinated to a military air force organization. The European agency, EASA, functions as a supervisor of the Member States, which are autonomous to investigate the air accidents that happened within their territories.

Analyzing the accident investigation practices we could not identify major differences as for the processes used by the United States, European Union and Brazilian agencies in terms of initial measures and practices adopted at the accident site. They are also similar as for the investigation team members, who later prepare reports, being observed some flexibility in the team structure depending on the characteristics of each accident. However, the agencies differ in terms of investigation systems. The way they perform independent investigations is ensured by international legislation. All International Civil Aviation Organization (ICAO) member countries are free to adopt the method and theory that lead them to the final report.

The philosophy of the investigation should follow the ICAO guidelines - Annex 13 (Aircraft Accident and Incident Investigation)[4], searching for elements that allow to prevent accidents and to ensure they are not used (primarily) to define responsibilities for the accident.

EASA has been taking the initiative of standardizing the communication of air accidents, in a process that in the future might make it easier to analyze such data and reduce air accidents or incidents.

In Brazil there is no integration of the air accident investigation. The three-member commission conducts an investigation focusing on employment data of work accidents. There is no exchange of information with the Defense Ministry, to which CENIPA is subordinated, and responsible to conduct investigations focusing on the air activity. When it was compared how investigations are carried out by the different agencies, it was observed that in the United
States and in Europe there is an integration of the different agencies, which complement themselves to offer a larger scope to the research of accidents, and thus, avoiding duplicity of investigations.

According to Eagle, Daves \& Reason [2] the research of the causes of a large-scale accident involve three steps: first, the facts are assembled in the sequence of events that occurred; a timeline is generated. This stage provides researchers with an indication of "when" things happened. Second, the active faults are identified. This step known as "job analysis" requires a description of a behavior of all personnel involved and gives researchers the knowledge "of what" happened. Third, it is performed an examination and assessment of the contribution of the latent failures. This step is an expansion of the analysis of the flow of information emphasizing the role of deficiencies during the work, and helps explain the "why" the accident occurred.

It was observed that the air accidents in Brazil follow the first and the second steps. However, the third step, i.e, the analysis of latent failures is poor, particularly as not all organizational aspects are evaluated. The safety culture has a strong influence on behavior representing values, and beliefs that are shared by group members, providing hints as how the group behaves in various situations. The culture also leads to various consequences, influencing adherence to rules and attitudes [6].

Comparing the work of aviation regulatory agencies, it was observed that the United States and European Union agencies integrate different elements that are complementary and give a more comprehensive approach on accidents reflecting a culture of integration.

\section{Conclusions}

The different ways of investigating air accidents among agencies lead to a lack of standardization of the statistics of air accidents, making it difficult to compare the data among world regions.

The Brazilian air accident investigation agencies have a close relationship with the government, and due to such subordination it is possible there are influences on the results about the contributory factors, especially the organization aspects.

Isolated analyses of the collected data do not allow a systemic view required to prevent aviation acci- 
dents. It also leads to duplicity of efforts among the investigation teams.

The American and European investigation systems suggest that a more integrated investigation system (when compared to the Brazilian one) allows a better information flow, thus making possible to generate preventive measures in all systems involved.

\section{References}

[1] CENIPA- Centro de Investigação e Prevenção de Acidentes Aeronáuticos. Available at:www.cenipa.aer.mil.br [accessed :Jun 20th, 2011].

[2] C.J. Eagle, J.M. Davies and J. Reason. Accident analysis of large-scale technological disasters applied to an anesthetic complication. Can J Anesth, (1992), 39: 2 , 118-22

[3] EASA- European Aviation Safety Agency Accident Statistics Europe - EASA Members States. EASA Meeting with AIB'S; 2008.

[4] ICAO - International Civil Aviation Organization. Aircraft Accident and Incident Investigation, Annex 13 to the Convention in Civil Aviation.Montreal,2001.

[5] National Transportation Safety Board. Annual Review of Aircraft Accident Data 2005: Washing ton DC; 2009 [accessed April 23th, 2011]Available at:http:/www.ntsb.gov/publictn/2009/ARCO901.pdf

[6] R.L. Helmreich and J.M. Davies, Culture, threat, and error: lessons from aviation. Can J Anesth (2004) 5 